\title{
Artigos
}

\section{As diretrizes curriculares nacionais da educação infantil: em busca de um trabalho pedagógico com qualidade}

Resumo: Desde quando creches e pré-escolas foram instituídas a atender educacionalmente a criança brasileira pela Constituição Federal de 1988, avanços foram tomados em se reivindicar a melhoria da Educação Infantil, como elevação da formação do profissional, repasse de verbas, construção de escolas, como também dispositivos legais foram elaborados para orientarem e definirem as práticas pedagógicas da Educação Infantil. Neste artigo pretende-se discutir sobre as Diretrizes Curriculares Nacionais para a Educação Infantil, que definem como devem ser organizadas as práticas pedagógicas, e analisar de que forma as atividades devem ser desenvolvidas nas instituições de Educação Infantil, a objetivar o desenvolvimento integral da criança em busca de um atendimento de qualidade desta etapa da educação básica.

Palavras-chave: Educação Infantil; diretrizes curriculares; práticas pedagógicas.

\section{The national curriculum guidelines of early childhood education: In search of a job to educational quality}

Abstract: Since when nurseries and pre-schools were established to serve
educationally Brazilian children by Federal Constitution of 1988, advances were
taken up claiming the improvement of early childhood education, such as raising
the professional training, transfer of funds, construction of schools, as well as legal
provisions have been drafted to guide and define the pedagogical practices of early
childhood education. This paper intends to discuss the National Curriculum
Guidelines for Early Childhood Education, which define how they should be
organized teaching practice, and examine how the activities should be developed
in early childhood education institutions, to objectify the holistic development of
children in seeking quality care this stage of basic education.
Keywords: Childhood Education; curriculum guidelines; pedagogical practices.

I Mestranda do Programa de Pós-Graduação em Educação Escolar - Universidade Estadual Paulista "úlio de Mesquita Filho" - Unesp / e-mail: alessandrafaria@hotmail.com 2 Doutora em Educação. Professora Assistente Doutor MS-3 do curso de Pedagogia na FCL/UNESP/Araraquara. Líder do GPEI/GEEl e da Escola Livre / FCLAr/UNESP. 

atendimento de qualidade para as crianças de 0 a 6 anos de idade, muitas conquistas foram conseguidas como retrocessos infelizmente aconteceram, mas pesquisadores, professores universitários, professores e educadores da Educação Infantil, e movimentos têm persistido em prol de melhorias desta etapa educacional.

Desde quando creches e pré-escolas foram instituídas a atender educacionalmente a criança brasileira pela Constituição Federal de 1988, avanços foram tomados em se reivindicar a melhoria da Educação Infantil, como elevação da formação do profissional, repasse de verbas, construção de escolas, como também dispositivos legais foram elaborados para orientarem e definirem as práticas pedagógicas da Educação Infantil.

Neste estudo iremos apresentar e discutir sobre as Diretrizes Curriculares Nacionais para a Educação Infantil (DCNEIs), que definem como devem ser organizadas as práticas pedagógicas na Educação Infantil.

Pensarmos na melhoria de qualidade ao atendimento da criança da primeira infância é também analisarmos de que forma as atividades devem ser desenvolvidas nas instituições de Educação Infantil, que são responsáveis em objetivar o desenvolvimento integral da criança atendida nesta etapa da educação básica.

Assim, nos interessa entendermos de que forma as diretrizes são definidas, entretanto, antes é necessário e importante sabermos como que a criança teve seu direito garantido a educação pelas políticas públicas.

\footnotetext{
4 Até à data, porém, nem a Associação de Editores e Livreiros nem o Instituto Português do Livro e das Bibliotecas nem o Observatório das Actividades Culturais ou a Biblioteca Nacional dispõem de dados estatísticos específicos relativos a este sector da produção editorial, o que impede a percepção objectiva da dimensão do fenómeno editorial dos livros para crianças. Recentemente, dados do jornal o Público, de 2 de Agosto de 2007 anunciavam que a Walt Disney Productions detém o maior número de traduções a nível mundial, o que dá conta de uma disneyzação global do mercado do livro para a infância, mas nem por isso uma medida da variedade editorial que concorre com esta hegemonia cultural de origem americana, particularmente em Portugal.

5 Desde o Prémio Hans Christian Andersen, instituído em 1956 e conhecido como o "Nobel" da Literatura para Crianças, com um prémio especial para ilustração desde 1966, à "Maçã de Ouro de Bratislava", Prémio da Bienal de llustração de Bratislava, instituído em 1967, ou o mais recente Prémio da Bienal Internacional de llustração para a Infância, llustrarte, inaugurada em 2003, no Barreiro (Portugal), entre tantos outros.
} 
Educação infantil: um direito da criança

Após anos de história de uma Educação Infantil de concepções e práticas assistencialistas, a criança de zero a seis anos tem instituído seu direito à educação pela Constituição Federal de 1988, e assim entendida como um sujeito de direitos, em que seu atendimento educacional deve ser garantido em creches e pré-escolas, sendo de dever do Estado e da família como também da sociedade.

Somente em 1996, com as Diretrizes e Bases da Educação Nacional nº 9.394/96, no artigo 29 que se define a Educação Infantil como primeira etapa da educação básica tendo a finalidade de promover o desenvolvimento integral da criança em seus aspectos físico, psicológico, intelectual e social. Na mesma lei no artigo 11, coloca-se a incumbência dos municípios o atendimento da Educação Infantil, mas destacando a prioridade e obrigatoriedade no ensino fundamental.

A LDB de 1996 vem reforçar a condição de direito da criança a educação, no entanto, como o foco da política estava no ensino fundamental de atendimento as crianças de 7 a 14 anos, e de caráter obrigatório, as outras etapas educacionais como a Educação Infantil ficaram em segundo plano, tanto em garantia das ofertas de vagas quanto no repassa de verbas para a sua sustentação.

Não é difícil imaginarmos os problemas decorrentes desta legislação, mesmo sendo uma conquista para a educação das crianças pequenas, ainda assim estas não são vistas com prioridade e nem mesmo com a importância necessária.

Conforme Assis (2006), o contexto que foi posto a Educação Infantil na época, insere esta na educação, mas a mesma legislação não lhe dá condições de expansão, melhorias, garantia de vagas, formação e valorização dos profissionais a atuarem nesta etapa educacional, ou seja, um direito que foi adquirido pela criança na lei, mas não efetivado na prática.

Além disso, cabe destacar que com a criação do FUNDEF - Fundo de Manutenção e Desenvolvimento do Ensino Fundamental e de Valorização do Magistério, que é um sistema nacional de redistribuição de impostos arrecadados de municípios, estados, com complementação da União, a serem repassados ao ensino fundamental, não envolveu a Educação Infantil, que careceu destes recursos ficando a cargo da manutenção municipal, e instituições educativas passaram por diversas dificuldades, como infraestrutura, materiais e recursos humanos.

Esta situação favoreceu para que municípios começassem a matricular crianças de 6 anos no ensino fundamental, o que não demorou para assistirmos a desarticulação da Educação Infantil, que permitiu pela Lei 11.114/05 a matrícula de crianças de 6 anos no ensino fundamental, e ao mesmo a tornou obrigatória pela ampliação do ensino fundamental de 8 anos para 9 anos. De acordo com Angotti (2006), a aceitação da Educação Infantil até 5 anos, desmancha os pequenos passos percorridos e conquistados para se estruturar esta etapa educacional sobretudo na legislação. 
Diante desta polêmica da Educação Infantil, há pesquisadores que defendam o ingresso das crianças de 6 anos no ensino fundamental preocupados com a alfabetização, argumentando que a pré-escola não dá conta deste processo por falta de preparo dos profissionais ou de qualidade da sistemática da Educação Infantil, ou até, por não haver a obrigatoriedade na Educação Infantil, e por isso não são todas as crianças que têm acesso e frequentam esta etapa educacional. E há aqueles que compreendem a necessidade da prática pedagógica específica à criança de 0 a 6 anos, como a importância ao acesso e permanência desta na Educação Infantil, lembrando ser um direito constitucional da criança. Esta problemática mais recentemente é abordada por Marcondes (2012), p. 21:

Entre os pesquisadores há divergências referentes aos pontos
positivos ou negativos dessa política. Há estudos que indicam que,
apesar da necessidade de se adequar a escola a uma nova realidade, tal
política é uma possibilidade de extinguir a fragmentação existente entre
Os dois níveis de ensino (KRAMER, 2006; SANTOS e VIEIRA, 2006;
BATISTA, 2006). Já os pesquisadores da área de Educação Infantil
consideram a proposta um retrocesso nos já consolidados direitos das
crianças de 0 (zero) a 06 (seis) anos de idade, os quais já eram
contemplados na Educação Infantil (ANGOTTI, 2007; FARIA, 2005).

De acordo com Angotti (2009), a desinformação e o desconhecimento sobre a infância estão distorcendo o que deveria ser feito com a criança como o seu direito educacional, pois na Educação Infantil o atendimento está na forma do cuidar-educar, do atendimento específico que deve ser oferecido a esta faixa etária considerando também a ludicidade, o brincar, e atividades em que: a alfabetização de mundo é importante para o desenvolvimento da criança e necessário para a alfabetização das letras, e que não pode ser deixada em segundo plano, e que desenvolvam as diferentes linguagens em educação como as da área da arte, e se utilize de jogos, brinquedos, e brincadeiras, a experimentação, e tudo mais que possa promover o desenvolvimento integral da criança.

Desde então, assistimos a inclusão destas crianças de 6 anos, quando não de 5 anos, no ensino fundamental, num atendimento educacional escolarizante próprio desta etapa educacional, em que o mobiliário é desconfortável, não há tempo para o lúdico, como também não há espaços externos, muitas horas em salas fechadas, o processo maçante da alfabetização, despreparo de profissionais, entre outros.

Independente das implicações que tecemos até aqui em relação que foi o ingresso da criança de 6 anos no ensino fundamental, cabe que esta agora nesta nova etapa educacional condição já posta pela legislação, seja atendida adequadamente e assim seu direito a educação garantido.

Mas, não podemos nos esquecer do direito das demais crianças de 0 a 5 anos no acesso e de um atendimento educacional de qualidade na Educação Infantil, que como qualquer outra etapa 
educacional precisa de investimentos para ter qualidade, como valorização de pesquisas e produção de conhecimento na área da primeira infância, definição legal e necessária na formação de professores e em nível superior, condições adequadas para este atendimento e permanência para as crianças nas instituições e de caráter educacional.

Recentemente com a promulgação da Lei no $12.796 / 13$ deste ano, as crianças da pré-escola de 4 e 5 anos passam a constar com a obrigatoriedade na educação básica brasileira, juntamente com o ensino médio. Esta situação gerou outra complicação que foi uma cisão da primeira etapa educacional entre creche e pré-escola, se pensarmos no direito de todas as crianças da Educação Infantil, podemos entender que de um lado tivemos um ganho, mas somente para as crianças de 4 e 5 anos, e por outro, as crianças menores de 3 anos permanecem na mesma condição, ou seja, é como se a pré-escola fosse mais importante que a creche, sendo que todas as crianças têm direito a educação e com qualidade.

E se compararmos do que ocorreu em relação na educação em decorrência das políticas educacionais até aqui, entre o ensino fundamental e educação infantil, corremos o mesmo risco de termos uma valorização e preocupação dos governos com a pré-escola, em detrimento ao atendimento da creche, fato que marca um retrocesso e enfraquecimento em tudo que demorou a ser conquistado na Educação Infantil. Da mesma forma, que entendemos a importância da Educação Infantil e do ensino fundamental, é importante e necessário o acesso à educação por todas as crianças da Educação Infantil conforme previsto na legislação, e a creche não pode continuar ou voltar a ser vista de modo assistencialista e desfavorecida, e agora diante da sua própria etapa educacional "Educação Infantil".

De acordo com Serrão (2012), a expansão do atendimento educacional próximo do ensino fundamental, da forma que se concentrou na pré-escola, pode ser compreendida como uma melhor aceitação social da escola para crianças mais velhas. Infelizmente, situação que constatamos até hoje na falta de compreensão da sociedade e até de profissionais que atuam na primeira infância, em compreender a importância deste atendimento educacional para as crianças.

Nos últimos anos, pesquisas e estudos de várias áreas, como a pedagogia, psicologia, psicanálise, sociologia, filosofia, neurologia, mais recente a neurociências, entre outros, concordam num consenso da importância de uma boa qualidade das vivências e experiências vividas nos primeiros anos de vida do indivíduo. Segundo Figueiró (2012) apud (Campos Jr³ 2009), também avalia a importância do trabalho com as crianças até 5 anos:

3 Ex-presidente da Sociedade Brasileira de Pediatria. 
[...] é quando o cérebro humano cresce quase que integralmente e sua estrutura se diferencia em funções complexas, que permitem a formação da inteligência, da capacidade de aprendizagem, do perfil da personalidade, do comportamento individual. Deixar de garantir esses cuidados à primeira infância prejudica a criança e reduz os resultados do investimento em educação nas etapas de vida seguintes.

Politicamente, a princípio observamos uma legislação educacional brasileira que se preocupa com a quantidade, fato este em promover acesso a todas as crianças, preocupação dos últimos governos de nosso país. Atualmente as discussões estão em torno da qualidade, já que garantir o acesso a todas as crianças não significa que tenham uma educação de qualidade.

Saviani (2007) em suas análises nas políticas públicas como a do PDE - Plano de Desenvolvimento Educacional, já apontava na época a preocupação do governo brasileiro em relação à qualidade da educação, após anos das políticas tratarem da expansão quantitativa do acesso às escolas, medidas foram tomadas a termos uma educação de qualidade para todos, mas o próprio autor diz que apesar das políticas públicas pretenderem buscar qualidade, estas não possuíam mecanismos em garantir êxito para isto.

Em 2006, o FUNDEF é substituído pelo FUNDEB que passa a destinar recursos financeiros para toda a educação básica, e assim, a Educação Infantil é contemplada a ser incluída no financiamento para a educação.

Mas mesmo a Educação Infantil sendo contemplada pelo FUNDEB, foi definida uma diferenciação chamada de fatores de ponderação, que causaram muitas controvérsias em relação ao custo por aluno entre as etapas e modalidades de ensino, a pré-escola ficou com índice de custo menor de 0,9 , enquanto a creche de 0,8 , sendo que o ensino fundamental obteve 1,0 , e o ensino médio de 1,20.

Precisamos pensar no direito à educação de toda a criança, que tem direito à Educação Infantil instituído na legislação, e não somente ao acesso, mas a qualidade de atendimento oferecida a atender e promover sua aprendizagem e desenvolvimento integral necessário e determinante para toda a sua vida. 
Se quisermos ter uma Educação Infantil de qualidade, medidas devem ser tomadas para que de fato este atendimento seja efetivo. Em busca na qualidade das práticas pedagógicas, Diretrizes Curriculares Nacionais Educacionais para a Educação Infantil (DCNEIs) foram elaboradas pelo Ministério de Educação e Desporto (MEC) em 1999 (e revisadas em 2009), a serem seguidas na organização de atividades cotidianas nas instituições de Educação Infantil.

Como colocado neste estudo, a Educação Infantil tem passado por muita movimentação, e diante de tudo que foi pesquisado e levantado por pesquisadores de diferentes áreas em prol do desenvolvimento da criança, é importante que as propostas pedagógicas possam desempenhar atividades educativas a considerar a criança como um sujeito histórico-social singular, cidadão, produtor e produto de cultura, que deve ser compreendida no seu modo de entender e significar o mundo.

Justamente atendendo as estas proposições, os DCNEIs no artigo $3^{\circ}$ estabelecem um currículo que busca conter práticas que articulem as experiências e os saberes das crianças com os conhecimentos que fazem parte do patrimônio cultural, artístico, ambiental, científico e tecnológico, de modo a promover o desenvolvimento integral de crianças de 0 a 5 anos de idade.

No artigo $4^{\circ}$ a criança deve ser considerada centro do planejamento curricular, um sujeito histórico e de direitos, reafirmando seu direito à educação já colocada na Constituição Federal de 1988, em que nas suas interações, relações e práticas cotidianas que vivencia, constrói sua identidade pessoal e coletiva, brinca, imagina, fantasia, deseja, aprende, observa, experimenta, narra, questiona e constrói sentidos sobre a natureza e a sociedade, produzindo cultura, e para tanto, a criança precisa ser ouvida e entendida na sua forma de significar o mundo e a si mesmo.

Conforme Oliveira (2010):

Esta definição de currículo foge de versões já superadas de conceber listas de conteúdos obrigatórios, ou disciplinas estanques, de pensar que na Educação infantil não há necessidade de qualquer planejamento de atividades, de reger as atividades por um calendário voltado a comemorar determinadas datas sem avaliar o sentido e o valor formativo dessas comemorações, e também da ideia de que o saber do senso comum é o que deve ser tratado com crianças pequenas. 
As DCNEIs partem de um conjunto de princípios que foram defendidos no processo de sua elaboração, que estão discriminados no seu artigo $6^{\circ}$, em princípios:

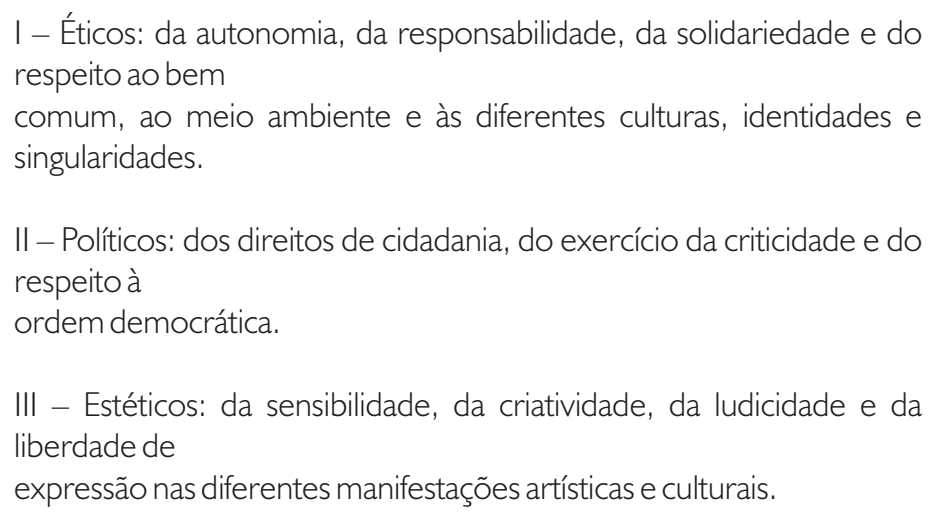

De acordo com Angotti (2006), as DCNEIs têm caráter mandatório, e devem ser respeitadas no âmbito nacional de todas as instituições de Educação Infantil. E de acordo com os princípios colocados a criança deve ser respeitada na sua individualidade e singularidade, na identidade, como um ser social, político, cidadã de direitos, produto e produtora de uma cultura. E para tanto, as práticas pedagógicas devem contemplar estes princípios na elaboração das atividades educativas a promover o desenvolvimento integral da criança.

É importante ressaltar a função sociopolítica e pedagógica da Educação Infantil colocada nas diretrizes no artigo $7^{\circ}$, que promovendo o atendimento em creches e pré-escolas deve ser um espaço que promova igualdade de oportunidades, e equidade educacional entre crianças de diferentes classes sociais, possibilitando o acesso aos diferentes bens de cultura e conhecimentos, construir novas formas de sociabilidade e subjetividades comprometidas com a democracia, a cidadania, a sustentabilidade do planeta, e com o rompimento de relações de dominação etária, socioeconômica, étnico-racial, de gênero, regional, linguística e religiosa que ainda marcam nossa sociedade.

De acordo com as DCNEIs no artigo $8^{\circ}$, o currículo deve ser desenvolvido num ambiente rico de experiências, estimulante, em que a criança tenha acesso e apropriação aos conhecimentos e as diferentes linguagens em educação, com direito à proteção, saúde, à liberdade, à confiança, ao respeito, à dignidade, à brincadeira, à convivência e à interação com outras crianças e de diferentes idades, como com os adultos, em que o cuidado é indissociável ao processo educativo (cuidareducar).

As práticas pedagógicas devem pelo artigo $9^{\circ}$ das diretrizes, ser norteadas por interações e brincadeiras, devendo garantir as seguintes experiências: 
I - promovam o conhecimento de si e do mundo por meio da ampliação de experiências sensoriais, expressivas, corporais que possibilitem movimentação ampla, expressão da individualidade e respeito pelos ritmos e desejos da criança;

II - favoreçam a imersão das crianças nas diferentes linguagens e o progressivo domínio por elas de vários gêneros e formas de expressão: gestual, verbal, plástica, dramática e musical;

III - possibilitem às crianças experiências de narrativas, de apreciação e interação com a linguagem oral e escrita, e convívio com diferentes suportes e gêneros textuais orais e escritos;

IV - recriem, em contextos significativos para as crianças, relações quantitativas, medidas, formas e orientações espaço, temporais;

$\checkmark$ - ampliem a confiança e a participação das crianças nas atividades individuais e coletivas;

VI - possibilitem situações de aprendizagem mediadas para a elaboração da autonomia das crianças nas ações de cuidado pessoal, auto-organização, saúde e bem-estar;

VII - possibilitem vivências éticas e estéticas com outras crianças e grupos culturais, que alarguem seus padrões de referência e de identidades no diálogo e reconhecimento da diversidade;

VIII - incentivem a curiosidade, a exploração, o encantamento, o questionamento, a indagação e o conhecimento das crianças em relação ao mundo físico e social, ao tempo e à natureza;

IX - promovam o relacionamento e a interação das crianças com diversificadas manifestações de música, artes plásticas e gráficas, cinema, fotografia, dança, teatro, poesia e literatura;

X - promovam a interação, o cuidado, a preservação e o conhecimento da biodiversidade e da sustentabilidade da vida na Terra, assim como o não desperdício dos recursos naturais;

XI - propiciem a interação e o conhecimento pelas crianças das manifestações e tradições culturais brasileiras;

XII - possibilitem a utilização de gravadores, projetores, computadores, máquinas fotográficas, e outros recursos tecnológicos e midiáticos.

Parágrafo único - As creches e pré-escolas, na elaboração da proposta curricular, de acordo com suas características, identidade institucional, escolhas coletivas e particularidades pedagógicas, estabelecerão modos de integração dessas experiências. 
As práticas pedagógicas devem também atender a criança com deficiência, transtornos globais de desenvolvimento, e altas habilidades/superdotação, adaptando assim, espaços, materiais, objetos e brinquedos para estas crianças, respeitando a política nacional inclusiva. Como também deve respeitar a diversidade, em que atividades deverão ser desenvolvidas a respeitar e valorizar a história e cultura de crianças afrodescendentes, e combate ao racismo e discriminação. Além disso, opção em adaptação de currículo por opção de povos indígenas, e também de crianças que residem no campo, como: agricultores, extrativistas, pescadores artesanais, ribeirinhos, assentados e acampados da reforma agrária, quilombolas, caiçaras, povos da floresta.

A avaliação na Educação Infantil segundo os DCNEIs no artigo $10^{\circ}$, não tem por objetivo, seleção, promoção ou classificação, mas sim pela observação crítica e criativa das atividades, das brincadeiras e interações das crianças no cotidiano. E para isto, diversas formas de registro podem ser utilizadas, como: portfólios individuais ou coletivos com fotografias ou atividades, vídeos, relatórios, desenhos, cartazes, ou seja, qualquer forma de registro que for decidido mais apropriado pela instituição. Os pais têm o direito de ter acesso a estes documentos avaliativos a fim de conhecerem o trabalho pedagógico feito com seu filho e acompanharem seu desenvolvimento.

A criança não deve ser retida na Educação Infantil em transição ao ensino fundamental, sua transição dentro da Educação Infantil deve ser feita de modo apropriado, sendo estabelecidas práticas pedagógicas que garantem a continuidade de seu aprendizado e desenvolvimento na próxima etapa, como por exemplo, de creche para a pré-escola.

O artigo $11^{\circ}$ é muito importante por tratar de como deve ser a prática pedagógica da criança na sua transição da Educação Infantil para o ensino fundamental, por isso a colocaremos na íntegra:

\footnotetext{
Na transição para o Ensino Fundamental a proposta pedagógica deve prever formas para garantir a continuidade no processo de aprendizagem e desenvolvimento das crianças, respeitando as especificidades etárias, sem antecipação de conteúdos que serão trabalhados no Ensino Fundamental.
}

A importância destacada no artigo acima é justamente para que uma etapa educacional não sobreponha a outra. Assim, como observamos o ingresso das crianças de 6 anos no ensino fundamental, cabe salientar que uma situação precoce em antecipar conteúdos do ensino fundamental para as crianças de 5 anos tem se propagado e se tornado bastante rotineiro nas instituições de Educação Infantil, não respeitando o desenvolvimento de cada idade. Conforme Marcondes (2012) em sua pesquisa, profissionais da Educação Infantil sinalizam a importância, por exemplo, de iniciar a alfabetização da criança mesmo não sendo a principal função desta etapa educacional, observando que as etapas finais cada vez mais se aproximam da cultura do ensino 
fundamental.

E pensarmos na qualidade das práticas pedagógicas na Educação Infantil, é atuarmos com atividades que promovam o aprendizado e o desenvolvimento adequado a cada faixa etária, respeitando a condição do infantil quanto para o fundamental, e é por isso, que as políticas elaboram diretrizes que definem atividades que respeitem as especificidades etárias. Conforme Marcondes (2012), p. 330:

\begin{abstract}
Há que se refletir sobre a cultura que compõe essas instituições e que permeiam todas as práticas pedagógicas que compõem esses contextos. Deve-se compreender que quem está nas instituições educacionais são, antes de tudo, crianças, tenham elas 05, 06 ou 10 anos. Sendo crianças, há que se pensar em todas as dimensões que as compõem, compreendendo que elas são cidadãs de direito e produtoras de cultura, portanto, ativas.
\end{abstract}

O importante é que com a definição das diretrizes para o currículo na Educação Infantil, pretende-se articular a experiência e os saberes da criança com conhecimentos que fazem parte do patrimônio cultural, artístico, científico e tecnológico da sociedade por meio de práticas planejadas e permanentemente avaliadas que estruturam o cotidiano das instituições. E para tanto, as práticas pedagógicas devem estar alicerçadas nas diretrizes em busca de qualidade nas atividades desempenhadas com a criança da primeira infância. 
Considerações finais

Diante de várias concepções e enfoques teóricos que foram dados ao longo dos anos à educação das crianças de 0 a 6 anos, tivemos um tipo de direcionamento realizado no atendimento e na formação, ou quando nem houve, de profissionais para atuarem na educação da primeira infância.

De modo geral, muito se persistiu com um atendimento de caráter social e assistencialista que infelizmente persiste em alguns casos até hoje enraizado nas instituições educativas, sobretudo em creches.

Por isto, foi importante neste estudo compreender que a criança da Educação Infantil é um sujeito, cidadã de direitos, que tem seu direito à educação, garantido pela legislação, mesmo que seja diante de uma etapa educacional obrigatória como passou a ser este ano a pré-escola, ou facultativo, no caso da creche. Independente da mãe trabalhadora, da condição social, econômica, ou qualquer outro fator, toda a criança tem direito à educação, e com qualidade, que quer dizer ser atendida com profissionais bem formados, práticas educativas de qualidade, e com demais condições adequadas ao atendimento educacional.

É fato, que a cisão ocorrida entre pré-escola e creche pelas políticas mais recentemente, veio atenuar e esmorecer o que se teve conquistado e consolidado de melhorias no atendimento da Educação Infantil, bem como o fortalecimento que estava sendo construído por anos de história de luta desta etapa educacional. Ainda, que muito deve ser discutido e refletido em relação à obrigatoriedade da pré-escola, que ficou de positivo desta última lei, somente no futuro poderemos contextualizar se de fato isto se concretizará.

Mas, o que sabemos, é que independente da inclusão da criança de 6 anos no ensino fundamental, da tendência crescente de escolarização precoce que passou à criança de 5 anos, a diferenciação em entendimento do que desarticulou a Educação Infantil entre pré-escola e creche, é que temos de pensar em práticas pedagógicas de qualidade que atendam estas crianças, diante de toda esta problemática posta pelas políticas públicas.

É conflitante verificarmos uma não correlação daquilo que entendemos ser necessário e importante para uma educação de qualidade, como recursos financeiros, conhecimento do desenvolvimento da criança, práticas pedagógicas, formação adequada de profissionais para atuarem nas diferentes etapas educacionais, com o que é colocado pelas políticas públicas educacionais.

Assim como a análise de Saviani, que verificou de positivo do governo federal em criar políticas que busquem qualidade no atendimento educacional, e não há mecanismos que nos garantem bons resultados, observamos também que na Educação Infantil há a intenção na elaboração das leis em melhorar o atendimento, no entanto, também não temos como garantir a 
efetivação destas, até porque a incumbência administrativa da Educação Infantil fica por conta dos municípios, e por mais que tenhamos a lei maior federal, as prefeituras possuem certa autonomia em gerir a educação municipal.

Especificamente neste estudo sobre as práticas pedagógicas da Educação Infantil, temos uma definição de diretrizes curriculares nacionais a serem seguidas para elaboração destas práticas que visam à qualidade de atendimento das crianças de 0 a 5 anos, mas efetivamente não podemos garantir que estas serão seguidas pelas instituições escolares.

Infelizmente, pela falta ou má formação de profissionais que atuam na Educação Infantil, fica difícil o entendimento de como deve ser o trabalho docente e as atividades educativas no cotidiano das instituições com a criança de 0 a 5 anos, já que dentro desta faixa etária há uma especificidade pedagógica para cada idade, principalmente a criança da creche. Há instituições que já seguem as diretrizes curriculares e entendem seu papel na promoção do desenvolvimento da criança, mas sabemos que muitas ainda desconhecem até os dispositivos legais que devem nortear as práticas pedagógicas.

Devemos analisar se os cursos de formação em pedagogia estão atendendo em preparar e capacitar professores com conhecimento a atuarem na Educação Infantil, ou até mesmo, pensarmos numa política de formação e atuação específica à docência.

As diretrizes, em geral como as demais leis, foram elaboradas a partir da escuta de educadores, pesquisadores, professores, movimentos, sociedade, e interessados na Educação Infantil, certamente nem tudo é considerado, mas há certo consenso naquilo que é conquistado e promulgado na lei, por mínimo que seja.

Atualmente, temos um embate em se conseguir ter qualidade na educação, entretanto, a busca deve ser incessante, as diretrizes aqui apresentadas devem sair do papel e, serem entendidas e aplicadas a garantir o direito de uma educação de qualidade para todas as crianças de 0 a 5 anos da Educação Infantil. 
Referências

ANGOTTI, M. (Org.), Educação infantil: Para quê, Para quem e Por quê? Campinas: editora Alínea, 2006.

Educação infantil: da condição de direito à condição de qualidade no atendimento, Campinas: editora Alínea, 2009.

ASSIS, M. S. S. Práticas de Cuidado e de Educação na Instituição de Educação Infantil: o olhar das professoras In: ANGOTTI, M. (Org.), Educação infantil: Para quê, Para quem e Por quê?, Campinas: editora Alínea, 2006.

BRASIL. Constituição da Republica Federativa do Brasil. Brasília, DF, Senado, 1988.

. Ministério da Educação. Lei de Diretrizes e Bases da Educação Nacional. LDB 9.394, de 20 de dezembro de

Ministério da Educação e do Desporto. Secretaria de Educação Fundamental. Diretrizes Curriculares Nacionais para a Educação Infantil. Brasília, DF: MEC/SEF/COEDI, 2009.

FIGUEIRÓ, J. A. Da violência à cidadania: o desenvolvimento de valores éticos na infância algumas contribuições da ciência. In: ANGOTTI, M. (Org.), A Educação Infantil em diálogos, Campinas: editora Alínea, 2012.

MARCONDES, K. H. B. Continuidades e descontinuidades na transição da Educação Infantil para o Ensino Fundamental no contexto de nove anos. Tese (Doutorado em Educação Escolar). Universidade Estadual Paulista, Araraquara, 2012.

OLIVEIRA, Z. de M. R. de. O currículo na educação infantil: o que propõem as novas diretrizes nacionais? In: I Seminário Nacional: Currículo em movimento - Perspectivas atuais, 2010, Belo Horizonte. Anais do I Seminário Nacional: currículo em movimento. Perspectivas atuais. Belo Horizonte: Universidade Federal de Minas Gerais, 2010. v. 1. p. 1-20.

SAVIANI, D. O Plano de Desenvolvimento da Educação: análise do projeto do MEC. Educação e Sociedade. Campinas, vol. 28, n.100, especial out.2007, p. 1231-1255. Disponível em: http://www.scielo.br/pdf/es/v28n100/a2728100.pdf. Acesso em 2013.

SERRÃO, C. R. B. A política da construção ou da justaposição: a Educação Infantil como $1^{a}$ etapa da Educação Básica Brasileira. In: ANGOTTI, M. (Org.), A Educação Infantil em diálogos, Campinas: editora Alínea, 2012. 